One patient who was originally normotensive became hypertensive while taking phenformin. The results of the University Group Diabetes Programme suggest that this may be a causal relation since phenformin treatment was associated with an increase in both heart rate and blood pressure. ${ }^{17}$ Hypertension in diabetics often indicates underlying renal disease, and patients with hypertension should not be given phenformin.

Screening is unlikely to be successful when the precipitating factor may be unpredictable, such as myocardial infarction, or when lactic acidosis develops spontaneously. Two of our eight patients had no clinical or necropsy evidence of a predisposing cause other than the drug. In another series ${ }^{5} 10$ out of 18 cases of lactic acidosis were apparently spontaneous, although hypertension was not considered.

In theory, screening should prevent many cases of lactic acidosis, but we doubt whether it is practicable in busy diabetic clinics and general practices. At present there is also insufficient awareness of the condition and its relation to phenformin. It was alarming that in five patients on phenformin the possibility of lactic acidosis was not considered even when the patient presented with vomiting. The difficulties of screening were further shown in the University Group Diabetes Programme study, where, despite extremely careful supervision, three out of 204 patients developed lactic acidosis and one died. ${ }^{17}$

Many potent drugs have serious side effects, but some continue to be used because they offer a unique benefit that outweighs the risk. This is not the case with phenformin, which is a weak hypoglycaemicagent. If a biguanide is indicated metformin should be used since it appears less likely to precipitate lactic acidosis. There are so many contraindications to the use of phenformin, excluding so many diabetics, that we believe that phenformin no longer has a place in the treatment of diabetes and should be withdrawn.

We thank our colleagues for permission to report details of patients admitted under their care; Dr G Walker and the staff of the department of clinical chemistry for their help; Mrs Jane Richards for invaluable secretarial help; and Mrs Lewis and the staff of the medical library for help with references.

\section{References}

${ }^{1}$ Walker, R S, Linton, A L, Thompson, W S T, British Medical fournal, 1960, 2, 1567.

2 Oliva, P B, American fournal of Medicine, 1970, 48, 209.

${ }^{3}$ Assan, R, et al, Diabetes, 1975, 24, 791.

4 Wise, P H, et al, British Medical fournal, 1976, 1, 70.

${ }^{5}$ Fulop, M, and Hoberman, H D, Diabetes, 1976, 25, 292.

${ }^{6}$ Conlay, L A, and Loewenstein, J E, fournal of the American Medical Association, 1976, 235, 1576.

${ }^{7}$ Blumenthal, S A, and Streeten, D H P, Annals of Internal Medicine, 1976, 84, 55.

${ }^{8}$ Dobson, H L, Diabetes, 1965, 14, 811.

${ }^{9}$ Editorial, 1973, 2, 27.

10 Vinik, A I, and Jackson, W P U, South African Medical Association, 1974, $48,2021$.

${ }_{11}^{11}$ Toghill, P J, et al, British Medical fournal, 1974, 3, 545.

12 Dembo, A J, Marliss, E B, and Halperin, M L, Diabetes, 1974, 24, 28.

${ }^{13}$ Sheppard, J M, et al, Australian and New Zealand fournal of Medicine, $1972,4,389$.

${ }^{14}$ Malins, J, Clinical Diabetes Mellitus, p 163. London, Eyre and Spottiswoode, 1968 .

15 Geigy Pharmaceuticals, Diabetes, 1976, 25, April.

${ }_{16}$ Winthrop Laboratories, Surrey, Circular letter, 25 August 1976.

17 Knatterud, G L, et al, Diabetes, 1974, 24, suppl No 1, p 65.

\title{
Combined one- and two-dimensional ultrasound system for monitoring fetal breathing movements
}

\author{
J W WLADIMIROFF, C M LIGTVOET, J A SPERMON
}

British Medical fournal, 1976, 2, 975-976

\section{Summary}

A combined one- and two-dimensional ultrasonic system for monitoring respiratory movements in the human fetus has been developed. A real-time cross-sectional image of the fetal chest at the level of the fetal heart can be obtained, and a time motion recording of fetal respiratory movements can then be written on a strip-chart recorder. Combining the features of one-dimensional and two-dimensional systems produces an accurate means of investigating fetal breathing movements.

\section{Introduction}

Fetal breathing movements were first observed with simple physical equipment at the end of the last century. ${ }^{1}$ Since 1971

\footnotetext{
Department of Obstetrics and Gynaecology, Academic Hospital Dijkzigt, Erasmus University, Rotterdam, The Netherlands J W WLADIMIROFF, MD, lecturer

Department of Experimental Echocardiography, Thorax Centre, Erasmus University, Rotterdam, The Netherlands

C M LIGTVOET, IR, scientist

J A SPERMON, IR, research fellow
}

several reports ${ }^{2-7}$ have been published on monitoring breathing movements in the human fetus with ultrasonic systems. We describe here the features of a combined one- and twodimensional ultrasound system, explain the investigation technique, and present some clinical results.

\section{The system}

For the study of human fetal breathing movements a multiscan system with a 20 -element linear array transducer is used. By fast electronic switching a two-dimensional cross-sectional image is built up with a repetition rate of 50 images per second. The ultrasound image is displayed on a television screen via a line converter. The converter uses real-time processing to obtain a high line density image consisting of 157 lines per frame. A detailed description of the multiscan system and the line converter can be found elsewhere. ${ }^{8} 9$

With two thumbwheel switches each of the displayed lines can be selected and the ultrasound data from the selected line can be used for a time motion recording. This line selection technique gives the investigator vital information on the position of the selected ultrasonic beam in relation to the scanplane (fig 1). The special time gain compensation enables the operator to eliminate echoes and subsequently to differentiate between various moving structures within a certain area.

\section{Investigation technique}

The multielement transducer is positioned on the patient's abdomen and a real-time cross-sectional image of the fetal chest at the level of 


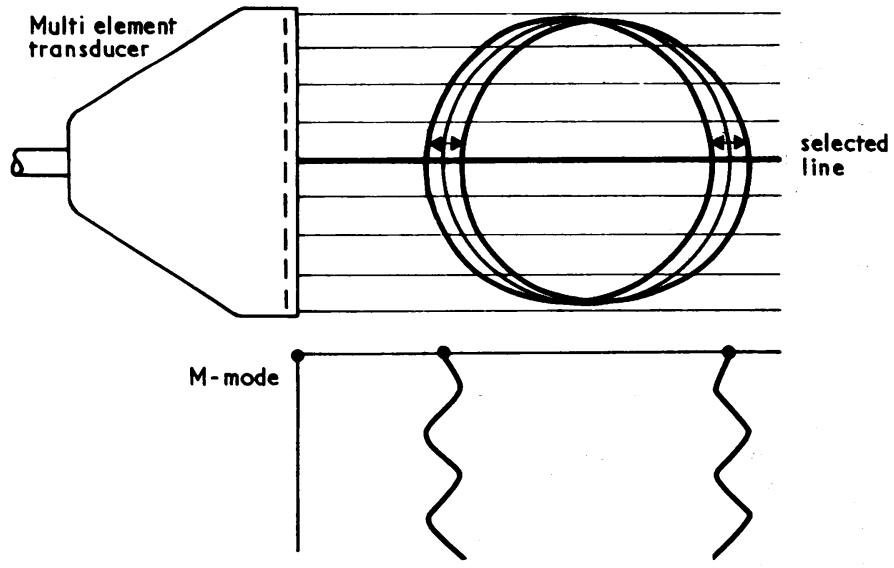

FIG 1-Diagram of line selection technique. Each ultrasound beam emitted by the multielement transducer can be selected, and ultrasound data from selected beam is registered as a time motion recording. Moving structures, which are perpendicular to the selected beam, can be analysed on the time motion recording.
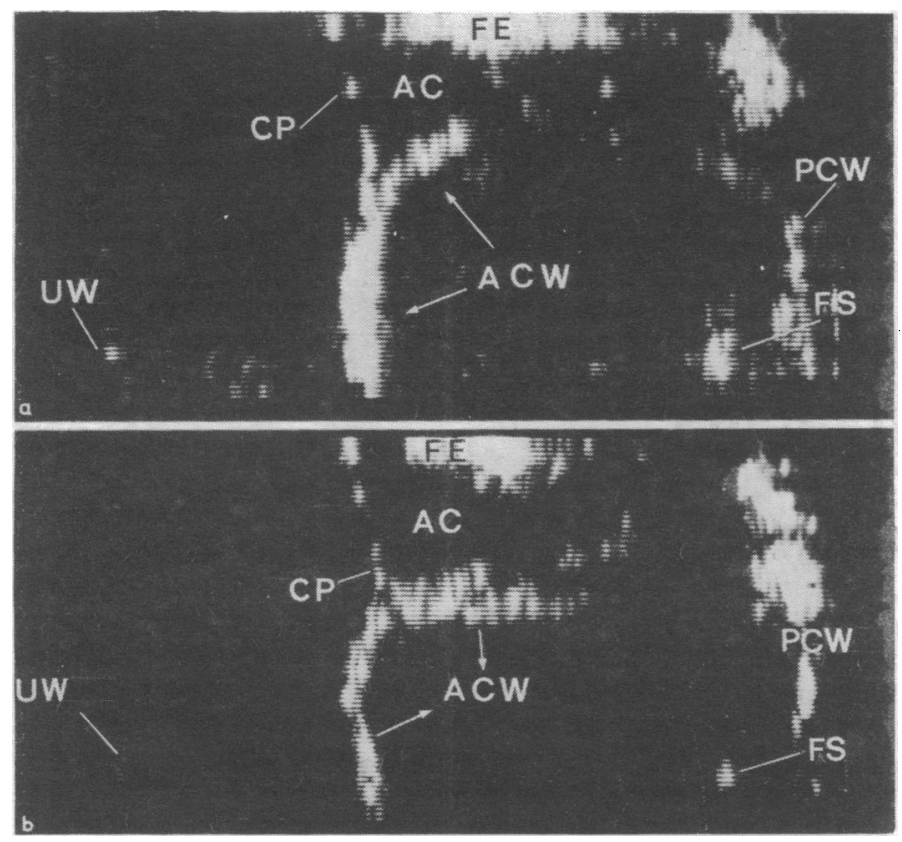

FIG 2-Real-time cross-sectional images of fetal chest at level of fetal heart $(a)$ in expanded position, $(b)$ in contracted position. Sound velocity: 1540 metres per second. Image display: $8 \times 16 \mathrm{~cm}$.

$\mathbf{U W}=$ Uterine wall. $\mathbf{C P}=$ Chorionic plate of placenta. $\mathbf{F E}=$ Fetal extremity. AC $=$ Amniotic cavity, ACW $=$ Anterior chest wall. $\mathbf{P C W}=$ Posterior chest wall. $\mathrm{FS}=$ Fetal spine.

the fetal heart is obtained. Fetal breathing movements are recognised immediately in the two-dimensional image. By using the special time gain compensation breathing movements can easily be differentiated from movements in adjacent structures, fetal body motion, and maternal breathing. The real-time two-dimensional imaging enables the investigator to adjust the position of the transducer to ensure that the line to be selected for time motion recording is perpendicular to that part of the fetal chest wall showing maximum breathing movements. The time motion recording and the maternal electrocardiogram (ECG) are written together on a strip-chart recorder. The two-dimensional images of the fetal breathing movements are registered on a videorecorder.

\section{Clinical results}

We have made 25 recordings so far, each lasting for 10 minutes. All the pregnancies were normal; they lasted from 32 to 40 weeks. Fetal breathing movements were observed during about $90 \%$ of the time. The registered movements were often shallow, although sometimes a displacement of the chest wall up to $7 \mathrm{~mm}$ was observed.

Fig 2 shows two images of a cross section of the fetal chest at the level of the fetal heart, one expanded $(2 a)$ and the other $(2 b)$ contracted.

Fetal breathing movements show an irregular pattern and usually have a frequency of 30-90 cycles per minute. Fig 3 shows a time motion recording of breathing movements together with maternal ECG.

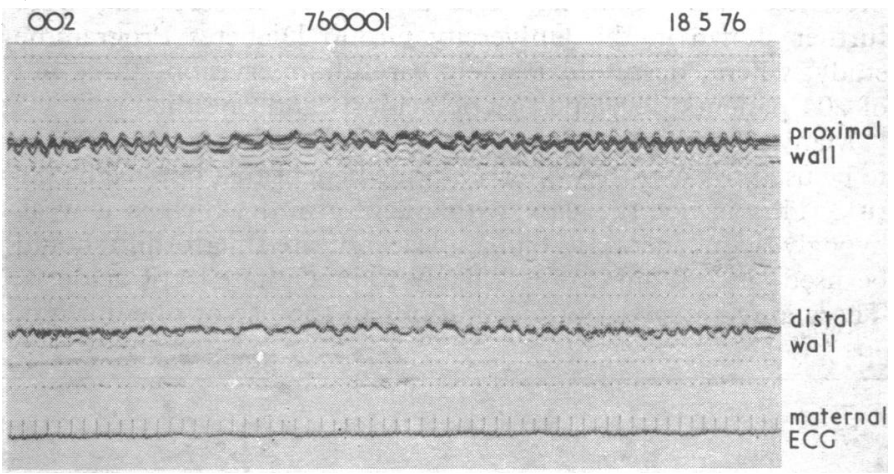

FIG 3-Time motion recording of fetal breathing movements together with maternal ECG. Distance between two dots is 0.5 seconds in horizontal and $1 \mathrm{~cm}$ in vertical direction.

\section{Discussion}

The clinical significance of breathing movements in the human fetus is still unknown, although depressed fetal breathing from mothers under heavy sedation ${ }^{5}$ and during fetal distress ${ }^{3}$ has been observed. Ultrasound offers the best technique for studying these breathing movements.

We believe that the best results can be obtained only with a system that combines the excellent structure recognition of a two-dimensional real-time system with a high line density image and the time motion recording of a one-dimensional system.

\section{References}

1 Ahlfeld, F, Verhandlungen der Deutschen Gesellschaft für Gynäkologie, p 203. Leipzig, von Breitkopf und Härtel, 1888.

2 Boddy, K, and Robinson, J S, Lancet, 1971, 2, 1231.

3 Boddy, K, and Dawes, G S, British Medical Bulletin, 1975, 31, 3.

4 Gennser, G, Marsal, K, and Brantmark, B, American fournal of Obstetrics and Gynecology, 1975, 123, 861.

5 Meire, H B, Fish, P J, and Wheeler, T, British fournal of Radiology, 1975, 48, 477.

- Bots, R S G M, and Broeders, G H B, Abstracts of the 5th European Congress of Perinatal Medicine. Uppsala, 1976.

7 Tremewan, R N, Aickin, D R, and Tait, J J, British Medical fournal, $1976,1,1434$.

${ }^{8}$ Bom, N, et al, Circulation, 1973, 48, 1066.

- Ligtvoet, C M, et al, Ultrasonics, in press. 